\title{
Effect of Mechanical Loading on the Oxidation Kinetics and Oxide-Scale Failure of Pure Ni
}

\author{
C. H. Zhou $\cdot$ H. T. Ma $\cdot$ L. Wang
}

Published online: 27 May 2009

(C) Springer Science+Business Media, LLC 2009

Erratum to: Oxid Met (2008) 70(5/6):287-294

DOI 10.1007/s11085-008-9121-2

There is an error in Fig. 1b in the original article. The data of weight gains under $10 \mathrm{MPa}$ and $20 \mathrm{MPa}$ CL was gained at $1073 \mathrm{~K}$ rather that at of $973 \mathrm{~K}$. The correct figure is as follows:

The online version of the original article can be found under doi:10.1007/s11085-008-9121-2.

C. H. Zhou $\cdot$ H. T. Ma $(\bowtie) \cdot$ L. Wang

School of Materials Science and Engineering, Dalian University of Technology,

Dalian 116024, People's Republic of China

e-mail: htma@dlut.edu.cn 

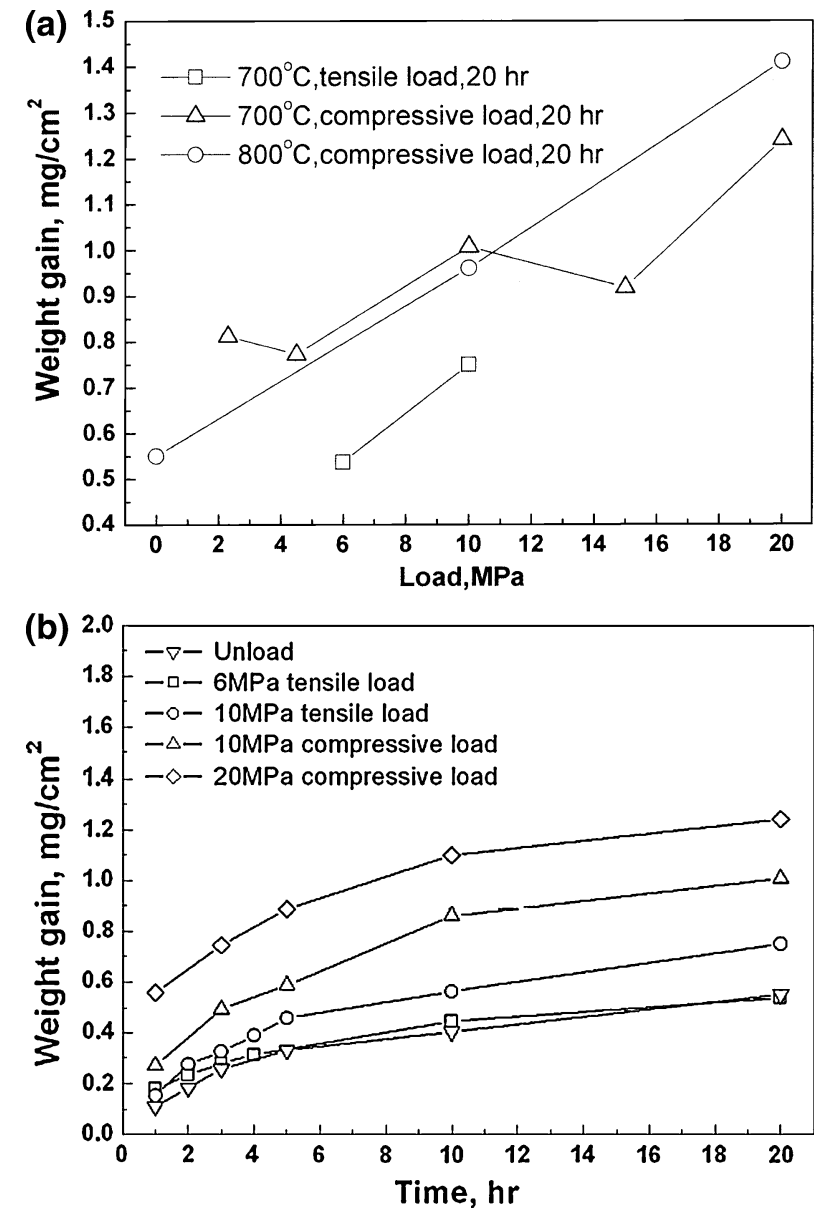

Fig. 1 Oxidation kinetics curves of pure $\mathrm{Ni}$ (a) the weight gain as a function of load for oxidation of $\mathrm{Ni}$ under TL and $\mathrm{CL}$ at $700-800{ }^{\circ} \mathrm{C}$ for $20 \mathrm{~h}$ and (b) the weight gain as a function of time for oxidation of $\mathrm{Ni}$ under TL and $\mathrm{CL}$ at $700{ }^{\circ} \mathrm{C}$ for $20 \mathrm{~h}$ 